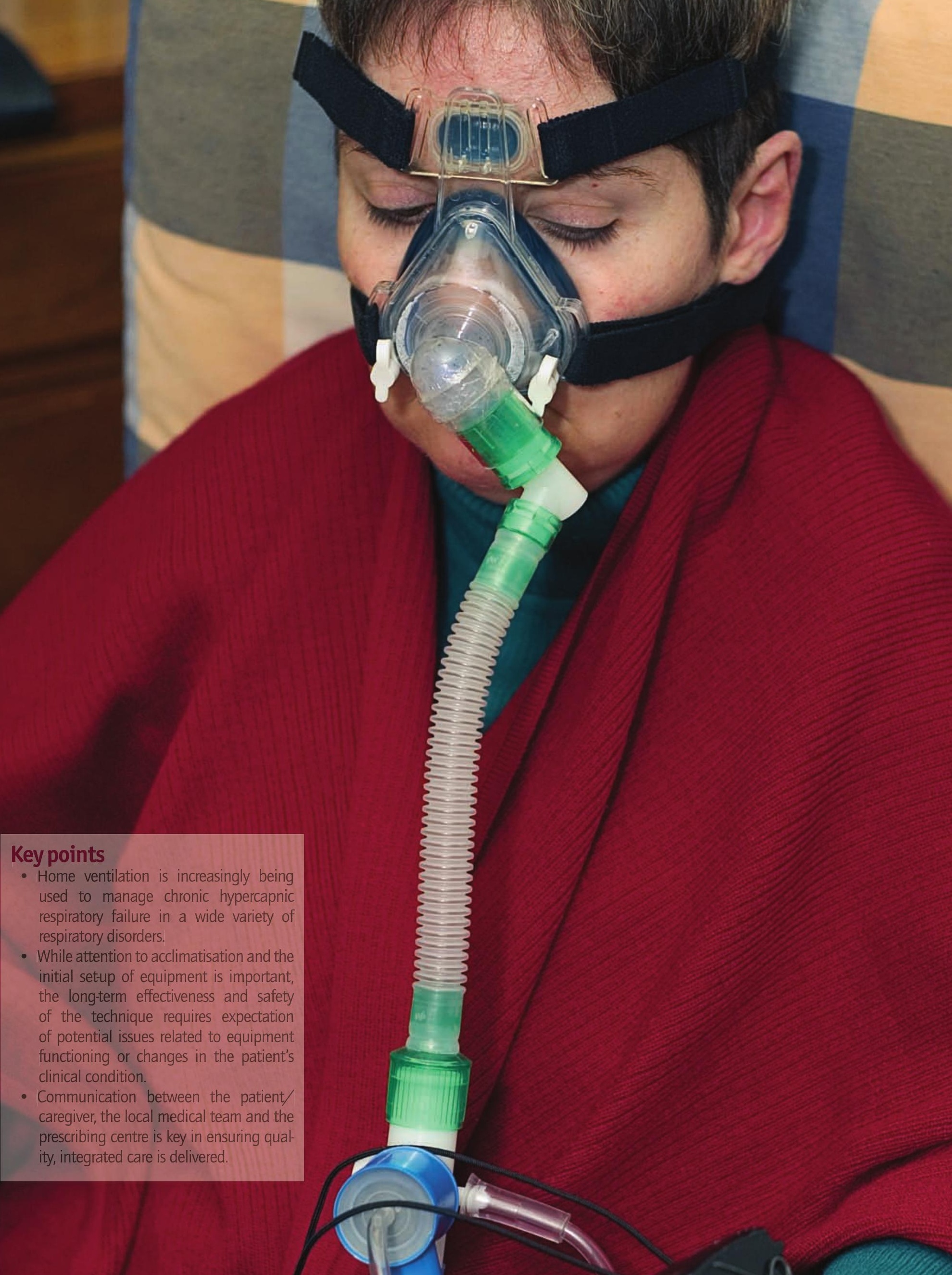




\section{Discharge planning and management for patients with chronic respiratory failure using home mechanical ventilation}

\section{Educational aims}

I To identify some of the clinical issues associated with the safe and effective care of the patient using home ventilatory support.

1 To recognise those patients and clinical situations where problems related to home ventilation are more likely to occur.

1 To assist in developing discharge plans to improve quality of care for patients using long-term home ventilation.

\section{Summary}

The use of home mechanical ventilation (HMV) to manage chronic respiratory failure (CRF) is becoming increasingly prevalent, and is usually delivered by means of a mask interface and pressure preset device. Although the transition from initial acclimatisation and prescription of ventilation to long-term home use is fairly straightforward for many patients with respiratory failure, issues such as nutrition, progressive ventilatory dependence and psychosocial problems can arise. Anticipating these problems and identifying resources and procedures that can reduce the negative impact of complex care carried out in the home is important for the long-term success and safety of HMV.

From the 1950s through to the early 1990s, HMV was limited to a relatively small number of individuals using negative pressure devices or receiving positive pressure ventilation through a tracheostomy. More recently, noninvasive ventilation (NIV) has emerged as an effective and acceptable approach to managing CRF outside of the hospital setting. The significant benefits of this therapy have been widely documented, and include relief of symptoms, improved quality of life, reduced need for unplanned hospitalisation and improved survival [1]. Consequently, over the past 20 years a dramatic increase in the number of individuals using HMV has occurred [1, 2]. HMV programmes now incorporate both ventilator dependent (>14-16 h per day ventilatory support) and ventilator assisted (primarily nocturnal only) individuals, using a variety of devices and interfaces, including invasive ventilation and NIV techniques (figure 1). However, the majority of patients being discharged home on ventilation are currently using masks and highly portable bilevel positive pressure devices (figure 2) [3]. The diversity of conditions and variability in level of care needed by these
A. Piper

Royal Prince Alfred Hospital Respiratory Medicine

Missenden Rd

Camperdown

Camperdown

New South Wales

2050

Australia

ajp@mail.med.usyd.edu.au

\section{Provenance}

Commissioned article, peer reviewed.

Competing interests

A. Piper has received travel support (Weinmann, Germany) and been involved in industry-sponsored educational sessions on behalf of ResMed (Asia-Pacific), Respironics (Australia) and Weinmann (Germany), manufacturers of equipment used in the diagnosis and treatment of sleep-disordered breathing. 
Figure 1

Outline of the various methods and techniques used for home ventilation.

\section{Figure 2}

Example of a simple bilevel ventilator and face mask commonly used for home ventilatory support. This equipment is particularly suitable for patients requiring nocturnal ventilatory support only.
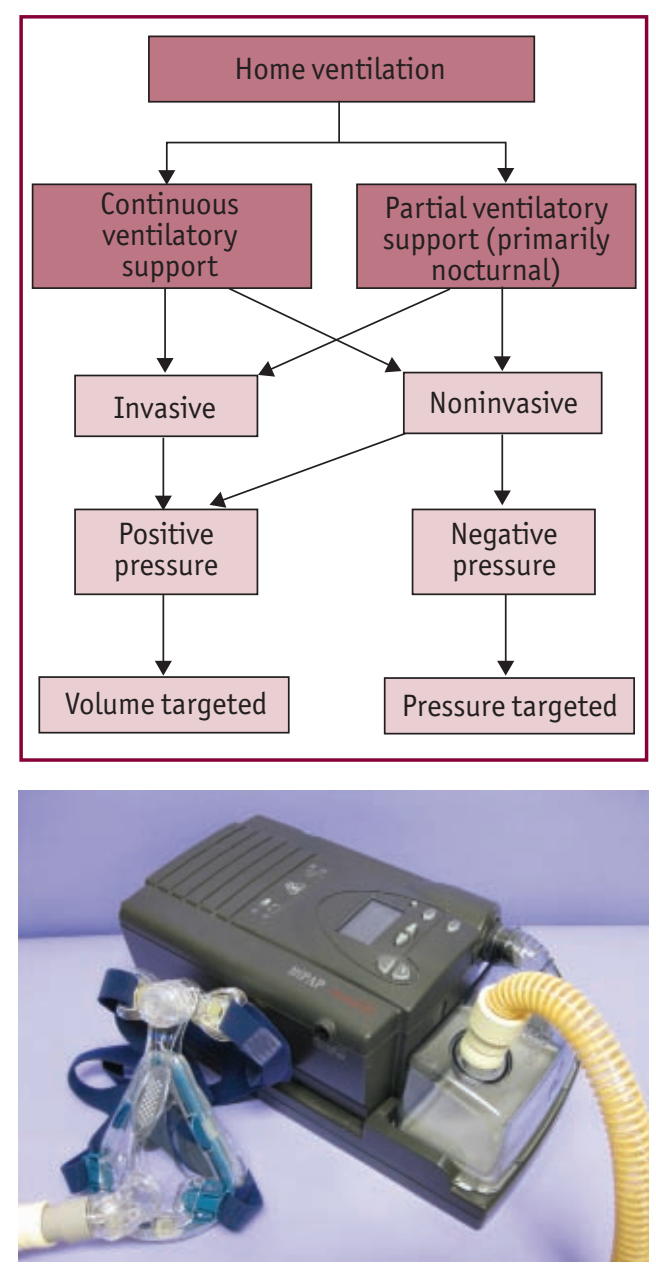

individuals means that introducing and maintaining long-term ventilation in the home requires skill and experience on the part of the prescribing centre, particularly if the patient is using ventilatory support on a near continuous basis or has a tracheostomy in place for the delivery of ventilation. Additionally, introducing medical technology into the home raises a number of issues for the patient and caregivers, as well as local health services, which need to be identified and
Table 1 Factors influencing the complexity of setting up and maintaining home ventilation

$\begin{array}{ll}\text { Clinical factors } & \text { Psychosocial factors } \\ \text { Indication for HMV } & \text { Patient/carer motivation } \\ \begin{array}{l}\text { Type of ventilator and mode of } \\ \text { ventilation needed }\end{array} & \text { Level of anxiety and ability to cope with therapy } \\ \text { Current stage of the disorder } & \begin{array}{l}\text { Presence of family/social supports if needed } \\ \text { Pevimity to medical facilities }\end{array} \\ \text { Comorbid conditions } & \text { Availability of appropriate community services } \\ \text { Likely progression of the disorder } & \text { Geographical isolation } \\ \text { Level of dependence on ventilatory } & \text { Personal and financial resources } \\ \text { support } & \\ \text { Presence of a tracheostomy } & \end{array}$

dealt with on an individual basis. Standardised protocols for managing and monitoring HMV are lacking, hindered by differences in organisational, administrative and funding structures not only between countries but often within different regions of the same country [4]. However, centres prescribing and discharging patients home on ventilation need to anticipate issues likely to arise during home ventilation use, and initiate monitoring and follow-up procedures to minimise such problems, to ensure therapy is carried out as effectively and safely as possible.

\section{Discharge planning}

Preparing the patient for discharge home on ventilatory support requires planning, the complexity of which will be greatly influenced by a number of clinical and psychosocial factors (table 1). Although most patients will be discharged home with simple bilevel devices for nocturnal use only, a small number of individuals will be tracheostomised and dependent on ventilatory support for all, or most, of the 24-h period despite attempts at weaning. Training, organising and funding appropriate equipment and resources for such individuals is more complex and time consuming and is best carried out, or directed by, centres more experienced in the process. Where an individual is unable to manage the ventilator equipment and ancillary care independently, and the caregiver and/or community resources are unavailable or insufficient to support the patient's ventilatory care needs, discharge home will not be feasible and placement in alternative long-term care facilities equipped to manage such individuals will need to be explored.

\section{Equipment choices}

\section{Ventilator type}

The first factor to consider is identifying the most appropriate type of ventilator for the individual patient and what mode it should be set in (table 2). The decision about the type of ventilator will be influenced by clinical, personal and financial issues, including the patient's underlying disease process and likely progression, the need for alarms, comfort of the delivered breath and the effectiveness of the device in maintaining ventilation, especially during sleep. Table 3 outlines some of the features and differences between the two major types of positive pressure ventilators: volume and pressure targeted. However, with the 
recent introduction of hybrid ventilators which are able to deliver both volume and pressure modes of ventilation, many of the best aspects of both types of ventilation have been incorporated into one machine and it is possible to programme a single machine to deliver either form of ventilation. Such devices are particularly useful for more ventilator-dependent patients, especially those using NIV for much of the 24h period where pressure-targeted ventilation may be more comfortable for sleep, while volume-targeted ventilation is more appropriate during the day. Although there are no formal guidelines regarding the most appropriate device for any particular diagnostic group, volume (and now hybrid) devices are more likely to be used for patients with neuromuscular [2] or brainstem/breathing control abnormalities, while patients with lung disease and obesity hypoventilation syndrome are more likely to be managed with pressure targeted devices [1]. In general, both volume- and pressure-targeted ventilation have been shown to be equally effective in correcting nocturnal and daytime gas exchange $[5,6]$, and this is reflected in the trend of increasing use of pressure preset for home ventilatory support, especially bilevel devices [1]. However, the ventilatory needs of the patient can change over time such that the device they were originally prescribed is no longer effective, and other forms of ventilatory support will need to be trialled [7]. Given that pressure-targeted ventilation is often more comfortable for the patient, while volume targeted provides a more consistent tidal volume despite changing respiratory mechanics, a number of pressure-targeted devices are now capable of automatically adjusting the inspiratory positive airway pressure (IPAP) to achieve a target tidal volume. Volume-targeted pressure support (also known as AVAPS or average volume assured pressure support on some devices) has been shown to increase minute ventilation and reduce $\mathrm{CO}_{2}$ during sleep to a greater extent than standard bilevel ventilation alone in patients with chronic respiratory failure [8]. However, at present there is no convincing evidence that this type of ventilation provides any longer term clinical advantages over standard volumeor pressure-targeted ventilation.

\section{Ventilator mode}

The mode or way in which each breath is delivered can be varied such that each breath is assisted (i.e. the patient's spontaneous effort triggers each breath from the ventilator, spontaneous mode), or controlled ("timed" with pressure-

\section{Table 2 Some of the decisions required when setting up ventilatory} support for home ventilation

\begin{tabular}{|c|c|}
\hline Decisions & Considerations \\
\hline $\begin{array}{l}\text { What is the most appropriate type of } \\
\text { machine: volume or pressure targeted? }\end{array}$ & $\begin{array}{l}\text { Likely variability in patient's respiratory } \\
\text { mechanics } \\
\text { Effectiveness on gas exchange } \\
\text { Patient comfort on the machine } \\
\text { Need for leak compensation by the device } \\
\text { Additional features required by the patient's } \\
\text { condition: } \\
\text { alarms } \\
\text { batteries } \\
\text { need for daytime mouthpiece ventilation } \\
\text { role in lung recruitment/breathing stacking } \\
\text { Cost }\end{array}$ \\
\hline $\begin{array}{l}\text { What mode of ventilatory support } \\
\text { will be most effective: spontaneous, } \\
\text { spontaneous-timed (assist-controlled) } \\
\text { or timed (controlled) }\end{array}$ & $\begin{array}{l}\text { Underlying disease process (diaphragm } \\
\text { efficiency especially in REM sleep; respiratory } \\
\text { drive) } \\
\text { Upper airway behaviour } \\
\text { Patient-ventilator synchrony } \\
\text { Comfort }\end{array}$ \\
\hline Settings, e.g. VT/IPAP, EPAP, rate & $\begin{array}{l}\text { Patient comfort and tolerance } \\
\text { Degree of upper airway instability } \\
\text { Impact on gas exchange and clinical symptoms } \\
\text { Goal of therapy }\end{array}$ \\
\hline $\begin{array}{l}\text { Interface: nasal, oronasal, prongs, } \\
\text { mouthpiece, total face, tracheostomy }\end{array}$ & $\begin{array}{l}\text { Comfort } \\
\text { Fit } \\
\text { Effectiveness } \\
\text { Nasal patency } \\
\text { Presence and severity of mouth leak } \\
\text { Patient preference } \\
\text { Ability to protect the upper airway }\end{array}$ \\
\hline Supplemental oxygen & Coexisting lung disease \\
\hline Humidification & $\begin{array}{l}\text { Upper airway dryness } \\
\text { Bypass of the upper airway } \\
\text { Thick secretions } \\
\text { Comfort }\end{array}$ \\
\hline
\end{tabular}

VT: tidal volume; IPAP: inspiratory positive airway pressure; EPAP: expiratory positive airway pressure; REM: rapid eye movement.

targeted devices, where the machine determines the breathing frequency), or a combination of both (termed assist-control with volume-targeted ventilators and spontaneous timed with pressuretargeted ventilators).

Where respiratory drive is not impaired, and spontaneous patient efforts are adequate to trigger the machine to support each inspiratory effort in all sleep stages, then a spontaneous mode of ventilatory support can be used. However, ineffective efforts are a common occurrence during nocturnal ventilation [9], related not only to inspiratory effort, but also respiratory 


\section{Table 3 Comparison of features of simple volume and pressure targeted} ventilators

\begin{tabular}{ll} 
Simple volume targeted ventilators & Simple pressure targeted ventilators \\
$\begin{array}{ll}\text { Able to deliver a more stable VT but at a } \\
\text { variable inspiratory pressure }\end{array}$ & $\begin{array}{l}\text { Able to deliver a stable peak inspiratory } \\
\text { pressure though } V \text { r can be variable }\end{array}$ \\
$\begin{array}{l}\text { May provide more effective ventilation } \\
\text { in the face of changing chest wall }\end{array}$ & $\begin{array}{l}\text { Usually provides more comfortable } \\
\text { ventilation }\end{array}$ \\
compliance or airway resistance & More resistant to leaks with respect to \\
Small to moderate leaks from system & achieving set peak inspiratory pressure \\
can reduce delivered $V$ T & Usually limited alarms \\
$\begin{array}{l}\text { Usually more extensive alarms } \\
\text { Internal battery }\end{array}$ & No internal battery \\
Higher cost & Lower cost \\
Suitable for air stacking & Not able to be used for air stacking \\
& Fewer gastrointestinal side-effects \\
Most commonly used with: & \\
ventilator dependent patients & Most commonly used with: \\
advanced neuromuscular patients & obesity hypoventilation \\
patients with low chest wall compliance & COPD \\
\hline
\end{tabular}

V: tidal volume; COPD: chronic obstructive pulmonary disease.

\section{Interfaces}

With NIV, the interface used will have a major impact on comfort and, therefore, acceptance of therapy by the patient. A poorly fitting interface will decrease the clinical effectiveness of treatment through leak, and may impact on adherence because of excessive side-effects. A wide range of mask styles are now commercially available, and while nasal, and to a lesser extent oronasal masks, are most commonly used, nasal prong and mouthpieces are also available (figure 3). The latter two interfaces are particularly useful for patients using NIV over more extended daytime periods, relieving pressure on the nasal bridge. Where a good mask fit cannot be made, custom masks can be moulded to better suit the anatomy of the patient's face.

Although nasal masks are most frequently used [2], mouth leaks are common and can impact on sleep quality, patient-ventilator synchrony and the amount of effective ventilation delivered to the patient [12]. A number of strategies have been employed to minimise leak, including chinstraps, mouth taping, reducing peak inspiratory pressure, switching to a pressure targeted mode of ventilation or using a full face mask. If leaks cannot be improved with these strategies, increasing pressure with pressure-targeted ventilation or tidal volume with volume-targeted ventilation can improve minute ventilation despite the higher leak [13], so long as such a strategy is tolerated by the patient. Chinstraps have been shown to reduce leak in some patients during nasal mask ventilation [14]. Oronasal masks can also be effective if a good fit can be achieved. However, care needs to be taken that this interface does not cause upper airway obstruction from pressure of the lower straps pushing the jaw back. If this does occur, it is most

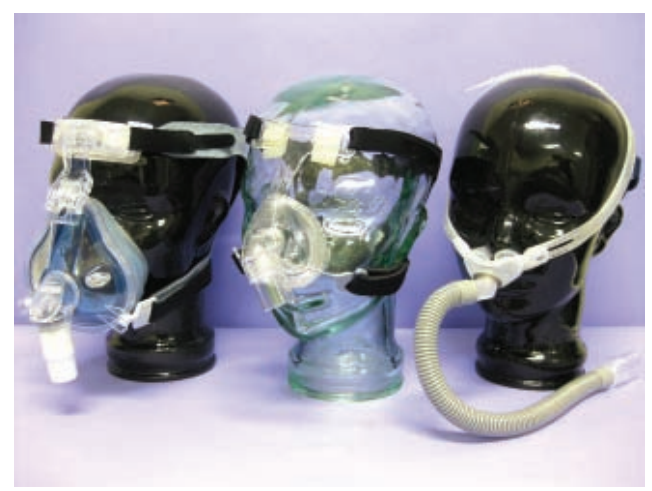

Figure 3

Some of the possible interfaces for use with noninvasive ventilation, including (from left to right): an oronasal mask, a nasal mask and nasal prongs. 
likely seen when the patient is in the supine position and in rapid eye movement sleep.

In the Eurovent survey [2], a significant minority of patients using home ventilation were tracheostomised, mainly those with a neuromuscular disorder. The reasons why a tracheostomy may be used include failure to adapt to NIV, inability to maintain effective ventilation with NIV, bulbar dysfunction with a high risk of ongoing aspiration and patient preference. While speech and swallowing can be adversely affected by the presence of a tracheostomy tube, the use of a cuffless tube can minimise the impact. Significant leaks can occur around an uncuffed tube and, if this occurs, an increase in tidal volume settings may be needed, especially for sleep. Passy Muir and other types of speaking valves can improve speech and swallowing, and can be used inline for ventilator dependent patients. When a cuffed tube is needed, a "talking" tracheostomy tube such as the Portex Trach Talk Blue Line tube could be trialled to see if this permits phonation.

\section{Humidification}

At present, the need for and most effective system of humidification during NIV has not been clearly defined. However, it is generally used in patients with thick secretions, or when upper airway dryness or nasal congestion becomes a problem. In a single session, crossover study performed in normal subjects, heated humidification during nasal NIV was shown to reduce the adverse effects of mouth leak on effective tidal volume, nasal resistance and improve overall comfort [15]. In a more recent 12-month crossover, randomised pilot study involving 16 patients receiving either heated humidification or heat and moisture exchanger, no difference in compliance or sideeffects with therapy were seen [16]. However, a higher number of patients decided to continue long-term NIV with heated humidification. For patients using home tracheal ventilation, heated humidification is usually used at night with a heat moisture exchanger for daytime use.

\section{Education and training}

Self management of ventilation equipment is a vital element for safe and effective home ventilation. In order to achieve this and reduce anxiety about home therapy, patients and caregivers need to be trained in using, cleaning and caring for the equipment, with periodic reassessment of their skills [17]. They should be provided with verbal and written information covering the nature of their disorder, a description of therapy and a follow-up plan of management (table 4). Training in the correct use of the equipment and basic trouble shooting skills is a fundamental requirement, with clearly outlined instructions on who to contact for routine as well as emergency situations and what defines such situations. A tracheostomy or need for near continuous ventilatory support will increase the complexity of discharge, training and home care requirements. This needs to be taken into account when planning discharge, as more services and resources will need to be organised. In particular, caregivers need to be trained to competently manage airway secretions either by suctioning if a tracheostomy is present, or by using manual and/or mechanical cough assist techniques for individuals using NIV. Identifying changes in the patient's medical condition, distinguishing these from a technical problem with the ventilator and the appropriate interventions to undertake are crucial aspects of education and training for home discharge of the more complex, ventilator dependent individual.

The importance of ensuring patients and their caregivers receive solid training in the use of the ventilator equipment is well illustrated by a study showing that apparent equipment malfunction is commonly a problem of improper care of the equipment or of equipment not being used correctly [18]. However, in a survey of 326 European centres providing home ventilation for $>20,000$ patients, FarRe et al. [19] found only $56 \%$ of centres assessed whether or not patients were able to correctly carry out the cleaning and maintenance of equipment. Emphasis on patient and carer management of HMV equipment is a key part of discharge home on therapy.

\section{Table 4 Areas of patient/caregiver education and training for HMV}

Outline of ventilatory support and why it is being used

Basic principles of how the ventilator works

Routine care and cleaning of the ventilator and accessories

Interface fitting

Basic troubleshooting and problem solving: technical and clinical problems

Understanding machine alarms and corrective measures to take

What constitutes an emergency and who to contact

Who to contact for technical support: non-emergency equipment problems and replacement of consumables

And if appropriate: airway clearance techniques including suctioning and manual/mechanical cough assist techniques

how oxygen therapy is used

tracheostomy management (care of the stoma site, tube management and suctioning) nutritional support 


\section{Clinical review, monitoring and ongoing support of patients}

Once a patient is discharged home using ventilatory support, a programme of regular review and monitoring both of their clinical status and equipment needs to be initiated. Despite considerable differences in patterns of home care and follow-up practices between countries [2], there are a number of common themes related to ongoing management of patients using ventilation devices in the home.

Periodic review of the patient by a specialised team should be arranged. The frequency and location of such reviews will depend on the severity, stage and progression of the patient's disorder, ease of transport, compliance with therapy and comorbid issues. In patients who are clinically stable and managing well, this may be annually. In contrast, for more complex less stable disorders or where problems using or managing therapy in the home are present, more frequent visits may be required. During these scheduled visits a number of activities may take place including routine checking or updating of equipment, monitoring of gas exchange and lung function, review of usage data and refresher training of patients/ caregivers in some aspect of home ventilation management (table 5). At other times, visits will

\section{Table 5 Checklist of activities that may be performed during periodic reviews of patients using HMV}

Review of blood gases and respiratory function

Downloading of machine usage

Clinical review of the patient:

relief of symptoms

sleep quality

ventilation related problems, e.g. skin breakdown, poor tolerance

changes in the primary disease: progression, weight change

Reassess equipment:

check settings and alarms

adequacy of cleaning

condition of interface, filters and tubing

mask fitting or alteration

Document and update any change to ventilator prescription

Review/retraining of patient/caregivers regarding home ventilation

Instigate further investigations where indicated:

swallowing and nutritional assessment

cough efficacy

cardiac investigations

polysomnogram or other overnight respiratory monitoring

Implement or review manual and mechanical cough assist techniques

Discussion of long-term therapy plan, limits on home ventilation and advanced care

directives

Referral to appropriate home and community services:

e.g. home nursing, respite care, community transport, community allied health,

pulmonary rehabilitation, palliative care

Communication of findings and ongoing management plan back to general practitioner be more involved, dealing with issues related to poor or noncompliance, identifying causes of ineffective ventilation, implementing changes to therapy if needed and ongoing discussion regarding escalation of therapy and advanced care directives.

For the very disabled, the ventilator dependent or the geographically isolated patient, scheduled reviews in a clinic may not be feasible or may be conducted infrequently. For these patients, more regular home visits by an outreach team, community health workers or private heathcare providers may be possible. However, such groups do not necessarily have the knowledge or skills to deal with patients using HMV [17]. Consequently, communication and flexible interactions between specialist centres with expertise in HMV and the patient's general practitioner/community staff with ready access to the patient's home is crucial.

Patients on HMV also need significant ad hoc assistance regarding ventilation. A recently published study assessed the frequency and types of calls received by a telephone support line provided by a regional home ventilation centre [17]. Over a 6-month period, this centre was responsible for supervising home ventilation for just over 1,200 adult and paediatric clients and received around 542 phone calls per month, or 5.5 telephone calls per patient per year. An earlier report of a tele-assistance programme which included a 24-h call line for patients with CRF $(70 \%$ of whom were on HMV) found an average of 0.5 (10.5) unplanned calls per patient per month were received [20]. These data highlight the high need for ongoing home support of patients receiving ventilation, both for general advice and to cope with emergency situations.

Changes in ventilator settings, interfaces and accessories are commonly needed once patients are sent home on ventilation. It is also important to periodically review what the patient has been prescribed and what they are actually using at home. FarRe et al. [3] found substantial differences between clinically prescribed and actual home ventilator settings, although the presence of these errors did not appear to correlate with the number of unscheduled hospital readmissions in the year prior to the study. However, how such inconsistencies may impact on compliance, sideeffects or overall patient comfort on therapy was not evaluated, but could potentially affect the patient's response to treatment.

In order to identify clinical changes and problems with ventilatory support, periodic monitoring is necessary. Previously this was carried out 
primarily in hospitals or sleep centres. However, advances in ventilator technology and monitoring capabilities are simplifying the identification of common problems encountered during home ventilation. A number of ventilators now allow storage of detailed data collected over several nights or longer. This information can be stored within the machine or on data cards, permitting data to be forwarded to the supervising centre or other local agency for downloading, analysis and, where necessary, change in therapy (figures 4 and 5). Where available, real time monitoring and consultative services through telemedicine options may also assist in the provision of better care for more dependent or geographically isolated HMV patients [21]. While still a relatively unexplored area, preliminary work has shown the potential value of telemedicine in monitoring and informing clinical decision-making in patients with respiratory failure using HMV [20].

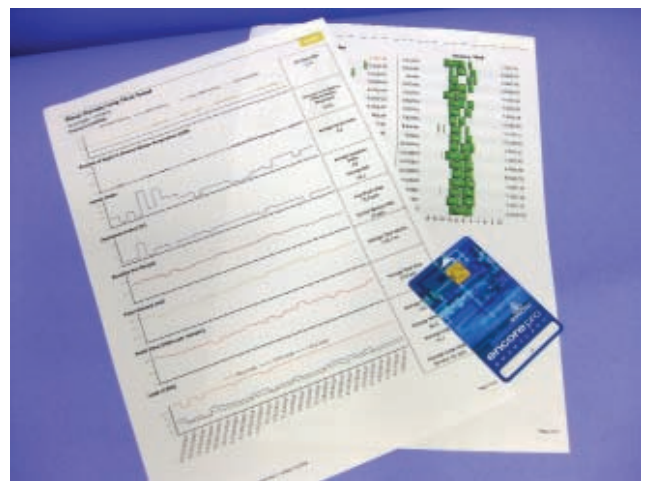

Figure 4

Smart cards and data download from home ventilators can provide clinically useful information regarding the effectiveness of ventilatory support over a prolonged time period. This information usually includes compliance, leaks, tidal volume or minute ventilation and machine settings.

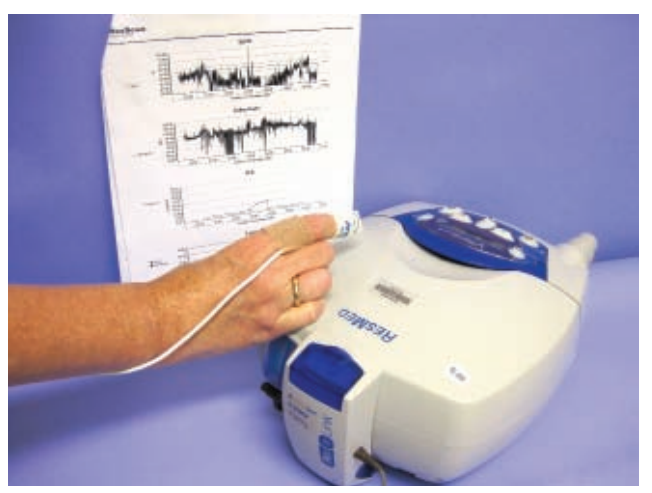

Figure 5

The addition of oximetry recordings to the download of machine performance can assist with clinical decision making regarding the effectiveness of current settings, the impact of events (e.g. leak) and the presence of persisting abnormal sleep breathing events.

\section{Risk management}

In providing ventilation in the home, both clinical staff and the patient need to acknowledge that interruption to ventilation for short periods is likely to occur. This may be related to either machine malfunction or maintenance schedules or to patient related factors such as nasal congestion, compliance issues or social reasons [22]. Identifying the possible consequences of such incidents is important to minimise the risks associated with HMV. Since the majority of patients on HMV use therapy primarily at night $[1,3,17]$, briefly suspending ventilation for a day or longer is possible before significant changes in symptoms or blood gases are seen [23]. However, serious consequences from ventilator malfunction can occur, especially in the more ventilator dependent patient [24], although the frequency and outcomes of such incidents are unknown [25]. In a prospective study of 150 ventilator patients over a 12-month period, nearly half of whom required 24-h ventilation, SRINIIASAN et al. [18] found episodes of equipment failure occurred in $74 \%$ of patients using ventilation continuously compared to around $40 \%$ in those using ventilation nocturnally or during sleep alone. Provision of a back-up ventilator for more ventilator dependent patients or those who are geographically isolated will limit the impact of any problems with the primary machine. Newer ventilator devices now frequently incorporate an automatic switch to an external battery in case of mains power failure, providing added safety for patients especially those unable to maintain independent ventilation while lying down. Attention should also be paid to setting up alarm systems and ensuring they are activated appropriately $[3,17]$.

\section{Additional considerations for the home ventilated patient}

\section{Secretion management}

In patients with neuromuscular disorders, instigating a secretion-management protocol is an essential component of any home management programme, and this needs to be carried out on a regular basis. The aim of assisted cough techniques is to reproduce the elements of a normal cough, including inflating the lungs to maximum insufflation capacity to improve expiratory peak flow rates and assist in propelling secretions 
upward and out. Lung recruitment strategies are an important element of this, the simplest approach being to use a manual resuscitation bag equipped with a one-way valve for breath stacking (figure 6). This can also be performed with a volume-targeted ventilator. The patient stacks consecutively delivered breaths with a closed glottis until the lungs have reached maximum capacity and then releases the breath. The goal of this technique is to maintain chest wall mobility and reverse some of the adverse effects of breathing at low monotonous tidal volumes. It is recommended that assisted-cough techniques are introduced when peak cough flow (PCF) falls below $270 \mathrm{~L}$ per min. Although a PCF of $<160 \mathrm{~L}$ per min is considered the level at which secretions cannot be effectively cleared [26], viral infections reduce inspiratory and expiratory muscle strength which will impact on the ability to clear secretions [27]; therefore, cough assistance techniques need to be introduced at a slightly earlier stage. The first step is to begin with breath stacking in conjunction with manually assisted-cough techniques [28] performed two to three times daily. The patient takes a maximal spontaneous inspiration and then uses breath stacking to increase the volume of air held in the lungs. The release of the breath is then timed with the carer applying a rapid abdominal thrust to mimic or augment abdominal muscle contraction. Using both manoeuvres together increases PCF and, hence, cough effectiveness more than either technique used in isolation. When manual techniques are no longer effective, mechanical insufflationexsufflation is required [28]. With this technique, positive pressure is applied to the airway to inflate the lungs (insufflation), followed by a rapid switch to negative pressure (exsufflation) to generate a high and sustained expiratory flow to mimic a more effective cough. The commercially available device is the mechanical cough assist device (Respironics, Murrysville, PA, USA), and has been shown to be more effective in increasing

\footnotetext{
Figure 6

Manual resuscitation bag with face mask and mouthpiece used to achieve maximum insufflation capacity in patients with respiratory muscle weakness. Note the presence of a one-way valve to assist in breath stacking.
}

peak cough flow than other cough augmentation techniques including manually assisted and NIV assisted cough [29]. An excellent overview of the practical aspects of this technique is provided by Chatwin [30] in a previous issue of Breathe.

However, these techniques require skill and coordination if they are to be performed effectively. Therefore, not only do the techniques need to be taught initially, periodic assessment of the caregivers skills in performing the technique is required. The effectiveness of cough assistance will be limited in the presence of bulbar dysfunction and this needs to be monitored in patients with motor neurone disease.

\section{Nutrition and weight loss}

Malnutrition can aggravate muscle wasting and fatigue, while obesity adds to the load placed on the chest wall. Both states can have an adverse impact on breathing and functional capacity, making mobility and general care of the patient more difficult. In those with neuromuscular disorders, weakness or poor coordination of the muscles for chewing and swallowing, reduced mouth opening, fatigue and breathlessness may reduce a patient's oral intake and increase the risk of malnutrition [31]. Similarly, if noninvasive ventilatory support is extended significantly into the daytime period, the time free for eating may be reduced [32]. Malnutrition has been shown to be a common problem for patients with neuromuscular and restrictive disorders using HMV [33], as well as in those with severe chronic obstructive pulmonary disease (COPD) where nutritional depletion has been associated with higher mortality [34]. Therefore, periodic assessment of the nutritional and swallowing status in patients using ventilation at home is important to determine if nutritional supplementation is required.

\section{Promoting physical activity and rehab}

One of the major goals of home care for patients with respiratory disorders is to improve function, improve quality of life and support independence [35]. While HMV is associated with improved quality of life [36] and exercise capacity [37], studies in COPD have demonstrated the potential additive effects of pulmonary rehabilitation in patients using NIV during sleep [38, 39]. Hence, consideration of a structured exercise programme in patients with CRF using HMV is warranted.

At present, most rehabilitation programmes are centre based, which could be a barrier for some HMV patients due to transport or distance issues. 
However, recent data from randomised trials have demonstrated that home rehabilitation can be a useful, equivalent alternative to outpatient rehabilitation in patients with COPD [40]. In patients with restrictive disorders already acclimatised to HMV, Borel et al. [41] demonstrated home exercise training with NIV is feasible, although the degree to which this provides additional benefits and in which patients compared with traditional exercise training alone has yet to be determined. The feasibility and benefits of using NIV-assisted home exercise training in COPD has not been reported. For patients prescribed HMV referral for exercise training should be considered.

For the patient with very severe respiratory impairment and shortness of breath on light exertion, ventilator-assisted ambulation is a feasible option [42]. However, some practical issues need to be addressed for patients wishing to use ventilatory support in this manner. The device, its power source (internal or external battery) and oxygen cylinder (if needed) must move with the patient. Although carrying this equipment in a backpack allows more unrestricted activity, the added weight of such a set up has been shown to be a major barrier to achieving benefits from NIV-assisted walking [43]. More practically, attaching the equipment to a rollator provides the benefits of improved walking and breathing efficiency associated with rollator use while avoiding the energy cost of carrying the machine [43]. Changes in ventilator settings or the interface are not necessary to derive benefit [42], so long as the patient is on adequate levels of inspiratory support and the device is capable of providing sufficient flow rates to meet ventilatory demand [44].

To facilitate mobility in the very weak or wheelchair-dependent individual, the ventilator can be attached to the wheelchair, and through either internal and/or external battery support, allow movement outside the home for prolonged periods. Either a nasal interface or mouthpiece can be used to provide this ventilatory assistance.

\section{Disease progression}

While the majority of patients using HMV can be managed by nocturnal NIV alone, for those with progressive disorders eventual progression to daytime use will be needed to maintain acceptable blood gases and to relieve symptoms. This may develop over months or years depending on the primary underlying process. An important aspect of this inevitable deterioration is anticipating the problem and providing appropriate supports for whatever treatment direction the patient decides. This includes changes in the range of interfaces available to the patient (figure 3), provision of a second ventilator and back-up battery, and possibly even a change in the type of ventilator used. Attention to nonrespiratory issues such as nutrition, mobility and the burden on carers is necessary.

The introduction of daytime periods of mouthpiece ventilation in addition to nocturnal ventilatory support has been shown to be a safe and effective ventilation option in patients with progressive neuromuscular disorders and breathlessness [45]. This will progress to continuous ventilation in some patients, and while most patients would prefer to continue the noninvasive approach to ventilation [46], a lack of knowledge and resources may limit this as a possible option, necessitating a tracheostomy. However, the placement of a tracheostomy is not without its problems, with higher rates of tracheal injuries, mucus hypersecretion and lung infections likely to occur compared to maintaining noninvasive ventilatory support [32]. Caregivers also require additional training and skill levels to manage a tracheostomy, and the greater degree of care and equipment management that the patient requires may be beyond the resources of the family. The progression to continuous ventilatory support with or without a tracheostomy may necessitate a change in living arrangements [32], and issues of access to and availability of suitable accommodation and care outside the home may arise. Such issues need to be raised and discussed with the patient well before the situation occurs. For those remaining at home, respite support for family carers will need to be arranged.

Usually continuous NIV is achieved using a mouthpiece during the day and a nasal or other type of interface at night. However, where patients cannot manage a mouthpiece, nasal mask or prong ventilation during the day is possible. For mouthpiece ventilation, a volume-targeted ventilator set in the assist-control mode with the rate at the lowest possible setting is used [47]. An angled mouthpiece allows back pressure in the circuit to prevent low-pressure alarming. The mouthpiece is held in place close to the patient's mouth, where an assisted breath can be taken whenever needed [45]. Since volume will be lost through leak, the tidal volume may need to be increased for comfort. Mouthpiece ventilation with simple pressure-targeted devices have also been reported in amyotrophic lateral sclerosis patients with intact bulbar function [48]. However, these devices do not permit breath stacking and have 
not been designed for continuous ventilatory support.

\section{Burden of home care}

A significant number of patients using HMV will require considerable assistance with daily living activities and this can significantly impact of the family's lifestyle and quality of life. The responsibility for high-technology equipment and the increased needs of these individuals may exaggerate feelings of anxiety and overload experienced by informal caregivers. Therefore, it is important to consider not only the individual requiring HMV, but also the family's needs and ability to cope when therapy is prescribed. A number of factors increasing the burden of HMV on informal caregivers have been identified [49], and include the level of dependence, the number of hours across the 24-h period that ventilation was required, the presence of a tracheostomy and distance between the patient's home and the hospital. It is important to identify patients and caregivers experiencing a high burden of care related to HMV, and ensure appropriate referral to home care services to provide additional assistance for both direct care tasks, such as bathing or equipment cleaning, or indirect care, such as housekeeping, shopping and transport.

\section{Conclusions}

The widespread availability of simplified devices for supporting breathing has lead to a rapid expansion of home ventilation for patients with a wide range of disorders associated with chronic hypercapnic respiratory failure. This therapy has the potential to provide substantial clinical, functional and survival advantages in appropriately selected patients. However, to ensure home therapy is continued in a safe, effective and sustainable manner, attention to potential problems and limitations of treatment need to be addressed. A key element of successful home ventilation therapy is the ongoing relationship between the patient, local health services including the general practitioner, and the specialist respiratory centre prescribing ventilatory support.

\section{References}

1. Janssens JP, Derivaz S, Breitenstein E, et al. Changing patterns in long-term noninvasive ventilation: a 7-year prospective study in the Geneva Lake area. Chest 2003; 123: 67-79.

2. Lloyd-Owen SJ, Donaldson GC, Ambrosino N, et al. Patterns of home mechanical ventilation use in Europe: results from the Eurovent survey. Eur Respir J 2005; 25: 1025-1031.

3. Farre R, Navajas D, Prats E, et al. Performance of mechanical ventilators at the patient's home: a multicentre quality control study. Thorax 2006; 61: 400-404.

4. Laub M, Berg S, Midgren B. Home mechanical ventilation in Sweden: inequalities within a homogenous health care system. Respir Med 2004; 98: 38-42.

5. Tuggey JM, Elliott MW. Randomised crossover study of pressure and volume non-invasive ventilation in chest wall deformity. Thorax 2005; 60: 859-864.

6. Windisch W, Storre JH, Sorichter S, et al. Comparison of volume- and pressure-limited NPPV at night: a prospective randomized cross-over trial. Respir Med 2005; 99: 52-59.

7. Smith IE, Shneerson JM. Secondary failure of nasal intermittent positive pressure ventilation using the Monnal D: effects of changing ventilator. Thorax 1997; 52: 89-91.

8. Ambrogio C, Lowman X, Kuo M, et al. Sleep and non-invasive ventilation in patients with chronic respiratory failure. Intensive Care Med 2009; 35: 306-313.

9. Fanfulla F, Taurino AE, Lupo ND, et al. Effect of sleep on patient/ventilator asynchrony in patients undergoing chronic non-invasive mechanical ventilation. Respir Med 2007; 101: 1702-1707.

10. Guo YF, Sforza E, Janssens JP. Respiratory patterns during sleep in obesity-hypoventilation patients treated with nocturnal pressure support: a preliminary report. Chest 2007; 131: 1090-1099.

11. Tsuboi T, Oga T, Machida K, et al. Importance of ventilator mode in long-term noninvasive positive pressure ventilation. Respir Med 2009; 103: 1854-1861.

12. Teschler H SJ, Ragette R, Konietzko N, et al. Effect of mouth leak on effectiveness of nasal bilevel ventilatory assistance and sleep architecture. Eur Respir J 1999; 14: 1251-1257.

13. Tuggey JM, Elliott MW. Titration of non-invasive positive pressure ventilation in chronic respiratory failure. Respir Med 2006; 100: 1262-1269.

14. Willson GN, Piper AJ, Norman M, et al. Nasal versus full face mask for noninvasive ventilation in chronic respiratory failure. Eur Respir J 2004; 23: 605-609.

15. Tuggey JM, Delmastro M, Elliott MW. The effect of mouth leak and humidification during nasal non-invasive ventilation. Respir Med 2007; 101: 1874-1879.

16. Nava S, Cirio S, Fanfulla F, et al. Comparison of two humidification systems for long-term noninvasive mechanical ventilation. Eur Respir J 2008; 32: 460-464.

17. Chatwin M, Heather S, Hanak A, et al. Analysis of home support and ventilator malfunction in 1211 ventilator dependent patients. Eur Respir J 2009; 35: 310-316.

18. Srinivasan S, Doty SM, White TR, et al. Frequency, causes, and outcome of home ventilator failure. Chest 1998; 114: 1363-1367.

19. Farre R, Lloyd-Owen SJ, Ambrosino N, et al. Quality control of equipment in home mechanical ventilation: a European survey. Eur Respir J 2005; 26: 86-94.

20. Vitacca M, Bianchi L, Guerra A, et al. Tele-assistance in chronic respiratory failure patients: a randomised clinical trial. Eur Respir J 2009; 33: 411-418. 
21. Smith SM, Elkin SL, Partridge MR. Technology and its role in respiratory care. Prim Care Respir J 2009; 18: 159-164.

22. Karakurt S, Fanfulla F, Nava S. Is it safe for patients with chronic hypercapnic respiratory failure undergoing home noninvasive ventilation to discontinue ventilation briefly? Chest 2001; 119: 1379-1386.

23. Masa Jimenez JF, Sanchez de Cos Escuin J, Disdier Vicente C, et al. Nasal intermittent positive pressure ventilation. Analysis of its withdrawal. Chest 1995; 107: 382-388.

24. Lechtzin N, Weiner CM, Clawson L. A fatal complication of noninvasive ventilation. N Engl J Med 2001; 344: 533.

25. Simonds AK. Risk management of the home ventilator dependent patient. Thorax 2006; 61: 369-371.

26. Bach JR, Saporito LR. Criteria for extubation and tracheostomy tube removal for patients with ventilatory failure: a different approach to weaning. Chest 1996; 110: 1566-1571.

27. Mier-Jedrzejowicz A, Brophy C, Green M. Respiratory muscle weakness during upper respiratory tract infections. Am Rev Respir Dis 1988; 138: 5-7.

28. Toussaint M, Boitano LJ, Gathot $V$, et al. Limits of effective cough-augmentation techniques in patients with neuromuscular disease. Respir Care 2009; 54: 359-366.

29. Chatwin M, Ross E, Hart N, et al. Cough augmentation with mechanical insufflation/exsufflation in patients with neuromuscular weakness. Eur Respir J 2003; 21: 502-508.

30. Chatwin M. How to use a mechanical insufflator-exsufflator "cough assist machine". Breathe 2008; 4: 321-325.

31. Willig TN, Paulus J, Lacau Saint Guily J, et al. Swallowing problems in neuromuscular disorders. Arch Phys Med Rehabil 1994; 75: 1175-1181.

32. Soudon P, Steens M, Toussaint M. A comparison of invasive versus noninvasive full-time mechanical ventilation in Duchenne muscular dystrophy. Chron Respir Dis 2008; 5: 87-93.

33. Cano NJ, Roth H, Court-Ortune I, et al. Nutritional depletion in patients on long-term oxygen therapy and/or home mechanical ventilation. Eur Respir J 2002; 20: 30-37.

34. Prescott E, Almdal T, Mikkelsen KL, et al. Prognostic value of weight change in chronic obstructive pulmonary disease: results from the Copenhagen City Heart Study. Eur Respir J 2002; 20: 539-544.

35. American Thoracic Society. Statement on Home Care for Patients with Respiratory Disorders. Am J Respir Crit Care Med 2005; 171: 1443-1464.

36. Windisch W. Impact of home mechanical ventilation on health-related quality of life. Eur Respir J 2008; 32: 1328-1336.

37. Schonhofer B, Dellweg D, Suchi S, et al. Exercise endurance before and after long-term noninvasive ventilation in patients with chronic respiratory failure. Respiration 2008; 75: 296-303.

38. Duiverman ML, Wempe JB, Bladder $\mathrm{G}$, et al. Nocturnal noninvasive ventilation in addition to rehabilitation in hypercapnic COPD patients. Thorax 2008; 63: 1052-1057.

39. Garrod R, Mikelsons C, Paul EA, et al. Randomized controlled trial of domiciliary noninvasive positive pressure ventilation and physical training in severe chronic obstructive pulmonary disease. Am J Respir Crit Care Med 2000; 162: 1335-1341.

40. Maltais F, Bourbeau J, Shapiro S, et al. Effects of home-based pulmonary rehabilitation in patients with chronic obstructive pulmonary disease: a randomized trial. Ann Intern Med 2008; 149: 869-878.

41. Borel J-C, Verges S, Pepin J-L, et al. Home exercise training with non-invasive ventilation in thoracic restrictive respiratory disorders: a randomised study. Respir Physiol Neurobiol 2009; 167: 168-173.

42. Dreher M, Storre JH, Windisch W. Noninvasive ventilation during walking in patients with severe COPD: a randomised cross-over trial. Eur Respir J 2007; 29: 930-936.

43. Dreher M, Doncheva E, Schwoerer A, et al. Preserving oxygenation during walking in severe chronic obstructive pulmonary disease: noninvasive ventilation versus oxygen therapy. Respiration 2009; 78: 154-160.

44. Menadue C, Alison JA, Piper AJ, et al. Non-invasive ventilation during arm exercise and ground walking in patients with chronic hypercapnic respiratory failure. Respirology 2009; 14: 251-259.

45. Toussaint M, Steens M, Wasteels G, et al. Diurnal ventilation via mouthpiece: survival in end-stage Duchenne patients. Eur Respir J 2006; 28: 549-555.

46. Bach JR. A comparison of long-term ventilatory support alternatives from the perspective of the patient and care giver. Chest 1993; 104: 1702-1706.

47. Boitano LJ, Benditt J0. An evaluation of home volume ventilators that support open-circuit mouthpiece ventilation. Respir Care 2005; 50: 1457-1461.

48. Bourke SC, Tomlinson M, Williams TL, et al. Effects of non-invasive ventilation on survival and quality of life in patients with amyotrophic lateral sclerosis: a randomised controlled trial. Lancet Neurol 2006; 5: 140-147.

49. Vitacca M, Escarrabill J, Galavotti G, et al. Home mechanical ventilation patients: a retrospective survey to identify level of burden in real life. Monaldi Arch Chest Dis 2007; 67: 142-147. 